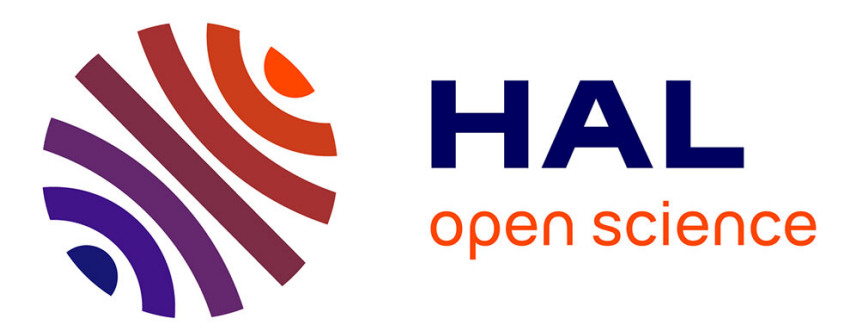

\title{
Sevoflurane for central catheter placement in neonatal intensive care: A randomized trial
}

Fabrice Michel, Renaud Vialet, Sophie Hassid, Claire Nicaise, Aurélie Garbi, Laurent Thomachot, Jean-Noël Di Marco, Pierre Lagier, Claude Martin

\section{- To cite this version:}

Fabrice Michel, Renaud Vialet, Sophie Hassid, Claire Nicaise, Aurélie Garbi, et al.. Sevoflurane for central catheter placement in neonatal intensive care: A randomized trial. Pediatric Anesthesia, 2010, 20 (8), pp.712. 10.1111/j.1460-9592.2010.03334.x . hal-00552647

\section{HAL Id: hal-00552647 https://hal.science/hal-00552647}

Submitted on 6 Jan 2011

HAL is a multi-disciplinary open access archive for the deposit and dissemination of scientific research documents, whether they are published or not. The documents may come from teaching and research institutions in France or abroad, or from public or private research centers.
L'archive ouverte pluridisciplinaire HAL, est destinée au dépôt et à la diffusion de documents scientifiques de niveau recherche, publiés ou non, émanant des établissements d'enseignement et de recherche français ou étrangers, des laboratoires publics ou privés. 


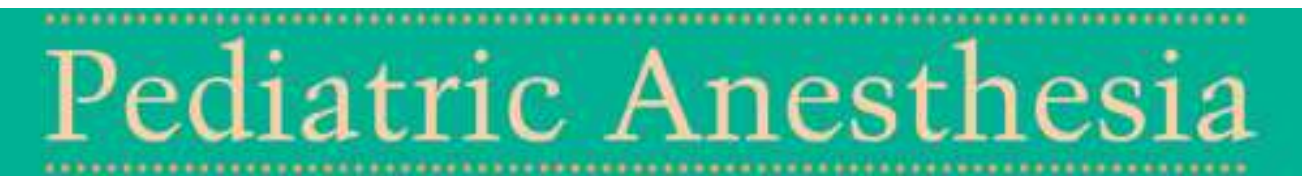

\section{Sevoflurane for central catheter placement in neonatal intensive care: A randomized trial}

\begin{tabular}{|c|c|}
\hline Journal: & Pediatric Anesthesia \\
\hline Manuscript ID: & PAN-2010-0068.R1 \\
\hline Manuscript Type: & Original Paper \\
\hline $\begin{array}{r}\text { Date Submitted by the } \\
\text { Author: }\end{array}$ & 18-Mar-2010 \\
\hline Complete List of Authors: & $\begin{array}{l}\text { Michel, Fabrice; Centre Hospitalier Universitaire Nord, Réanimation } \\
\text { Pédiatrique et Néonatale } \\
\text { Vialet, Renaud; Centre Hospitalier Universitaire Nord, Réanimation } \\
\text { Pédiatrique et Néonatale } \\
\text { Hassid, Sophie; Centre Hospitalier Universitaire Nord, Réanimation } \\
\text { Pédiatrique et Néonatale } \\
\text { Nicaise, Claire; Centre Hospitalier Universitaire Nord, Réanimation } \\
\text { Pédiatrique et Néonatale } \\
\text { Garbi, Aurélie; Centre Hospitalier Universitaire Nord, Réanimation } \\
\text { Pédiatrique et Néonatale } \\
\text { Thomachot, Laurent; Centre Hospitalier Universitaire Nord, } \\
\text { Réanimation Pédiatrique et Néonatale } \\
\text { Di Marco, Jean-Noël; Centre Hospitalier Universitaire Nord, } \\
\text { Réanimation Pédiatrique et Néonatale } \\
\text { Lagier, Pierre; Centre Hospitalier Universitaire Nord, Réanimation } \\
\text { Pédiatrique et Néonatale } \\
\text { Martin, Claude; Centre Hospitalier Universitaire Nord, Réanimation } \\
\text { Pédiatrique et Néonatale }\end{array}$ \\
\hline Key Words: & $\begin{array}{l}\text { Newborn, Sevoflurane, Peripherally inserted catheter, procedural } \\
\text { pain, neonatal intensive care, sedation }\end{array}$ \\
\hline
\end{tabular}




\title{
Sevoflurane for central catheter placement in neonatal intensive care: A randomized trial
}

\author{
Fabrice Michel, ${ }^{1,2}$ Renaud Vialet ${ }^{2}$ Sophie Hassid, ${ }^{2}$ Claire Nicaise, ${ }^{2}$ Aurélie Garbi, ${ }^{1,2}$ \\ Laurent Thomachot, ${ }^{2}$ Jean Noël Di Marco, ${ }^{2}$ Pierre Lagier, ${ }^{2}$ Claude Martin ${ }^{1,2}$ \\ 1. Faculté de Médecine de Marseille - Université de la Méditerranée. Marseille. France. \\ 2. Unité de réanimation pédiatrique et néonatale - Centre Hospitalo-Universitaire Nord, \\ Marseille, France. Assistance-Publique Hôpitaux de Marseille
}

Short title: Sevoflurane for catheter insertion in newborn

\section{Correspondance to: \\ Dr Fabrice MICHEL}

Unité de Réanimation Pédiatrique et Néonatale et Unité de Brûlés Pédiatriques - Centre Hospitalo-Universitaire Nord - 13915 Marseille Cedex 20 - France.

E-mail : fabrice.michel@ap-hm.fr / Fax number: 33491964661 / Phone number: 334 91968659

Key words: Sevoflurane, newborn, peripherally inserted catheter, pain, sedation, neonatal intensive care

Conflict of interest: none 


\begin{abstract}
Objective: To compare the efficacy and safety of sevoflurane deep sedation with glucose and non-nutritive sucking (GNNS) in reducing the duration of the procedure and in preventing pain-related effects during peripheral inserted central catheter (PICC) placement.

Background: PICC placement in neonatal intensive care is a delicate and stressful procedure that requires pain prevention. GNNS have been recommended in this situation but remain often inefficient.
\end{abstract}

Methods: We designed a randomized controlled study in a sixteen-bed paediatric and neonatal unit in a tertiary hospital. Fifty-nine neonates at $>28$ weeks of gestation with CPAP or invasive mechanical ventilation and requiring PICC placement were included. Patients were randomized to receive inhaled sevoflurane (IS) or glucose and non-nutritive sucking (GNNS). Procedural duration and conditions, hemodynamic and respiratory parameters, occurrence of movements and complications were compared (http://clinicaltrials.gov trial register no. NCT00420693).

Results: The 2 groups had similar demographics. There were no between group differences in procedural duration $(\mathrm{p}=0.84)$ despite greater immobility in IS group $(\mathrm{p}=0.017)$. IS was also associated with fewer episodes of hypertension $(\mathrm{p}=0.003)$, tachycardia $(\mathrm{p}<0.001)$ and bradycardia $(\mathrm{p}=0.02)$. Occurrences of hypotension were not different between groups $(\mathrm{p}=0.06)$. The GNNS group showed more desaturation during the 4 hours after the procedure $(\mathrm{p}=0.03)$. Complications during intensive care stay did not differ between groups.

Conclusion: Inhaled sevoflurane does not make easier catheters placement but prevent painrelated symptoms. Since sevoflurane is responsible for hypotension, it requires careful monitoring and treatment adaptation. 


\section{Introduction}

Despite expert recommendations, pain-control measures in neonates, especially in preterm neonates undergoing invasive procedures are limited in most neonatal intensive care units (NICUs) (1).

Peripherally-inserted central catheters (PICCs) are widely used in NICUs, however, placement of these very thin catheters is a delicate and stressful procedure, often requiring several punctures and prolonged handling. Topical anaesthesia and non-nutritive sucking, recognized as efficient in routine procedures (2), are frequently insufficient for line placements, particularly because most of these procedures do not result in successful placement on the first attempt (3). The pharmacokinetic and pharmacodynamic properties of opioids (4) and benzodiazepines in neonates make them unpredictable, both in regard to their effectiveness in reducing pain and in terms of their side effects (3). In ventilated patients, these medications can prolong mechanical ventilation.

Sevoflurane enables rapid induction and recovery and is easily titratable with predictable results. The results of a prospective randomized trial for intubation in neonates (6) and for sedation, conserving spontaneous breathing, in children undergoing MRI, suggest that sevoflurane may be helpful to reduce pain manifestation during PICC placement in neonates (7).

In a preliminary study, we showed the feasibility and efficiency of inhaled sevoflurane for central venous catheterization in spontaneously breathing term and preterm neonates in the NICU (8). Based on these findings, we designed a randomized controlled study comparing sevoflurane inhalation with glucose and non-nutritive sucking in preventing pain-related effects during PICC placement in neonates. The primary outcome was the ease in performing PICC placement, determined by duration of the procedure. Secondary outcomes included the efficacy and tolerance of treatments. 


\section{Methods}

This prospective randomized study was performed in a French tertiary center care and was approved by our ethics committee. Written informed consent was obtained from the parents of all children. (http://Clinicaltrials.gov trial register no. NCT00420693).

\section{Patients and groups}

Neonates between 28 to 41 weeks of gestational age, requiring PICC were included in this study. Patients were excluded if they had received analgesic treatment; if they had a neurological disorder; if they had hemodynamic instability, defined as hypotension requiring treatment; and if they had contraindications to sevoflurane administration. Ventilated neonates were also excluded except if extubation was programmed in the 6 hours after PICC placement. All the mechanically ventilated patients were intubated nasally, according to our practice.

Patients were randomly assigned, using sealed envelopes, to receive inhaled sevoflurane (IS) or glucose and non-nutritive sucking (GNNS). Groups were stratified according to ventilation support: nasal CPAP (infant-flow®) or invasive ventilation (synchronized intermittent mechanical ventilation (Evita 4; Drager; Germany)). Neonates were not sedated during mechanical ventilation.

All neonates received local anaesthesia with a lidocaïne and prilocaine (Emla cream 5\%) dressing 45 min before PICC.

\section{Treatment administration}

Glucose $30 \%(0.2 \mathrm{ml})$ was administered through a pacifier used for non-nutritive sucking, before the puncture and during all procedures according to clinical evaluation.

Sevoflurane was administered in a ventilated room (6 total air changes/h), using equipment and facilities suitable for general anaesthesia. Three hours before the beginning of the procedure, enteral nutrition was stopped and the stomach was emptied by aspiration of the 
gastric tube and compensate by an increase of parenteral alimentation for the time of procedure. Pulse oximetry $\left(\mathrm{SpO}_{2}\right)$, heart rate $(\mathrm{HR})$, cutaneous temperature, respiratory rate (RR) and transcutaneous carbon dioxide $\left(\mathrm{tcCO}_{2}\right)$ were monitored continuously. Non-invasive arterial pressure was measured every 3 minutes. The sevoflurane evaporator was installed on an external fresh gas delivery system. This fresh gas was added to the gas of either the CPAP or the respirator, via the heater, with a flow rate of 4 to $8 \mathrm{~L} \cdot \mathrm{min}^{-1}$. Fresh gas flow of the Infant CPAP was decreased to maintain the expiratory pressure between 3 and $5 \mathrm{cmH} 2 \mathrm{O}$. The Infant Flow system allowed gas administration with very low nasal leak and the installation of an anaesthetics gas scavenging filter to trap waste gases at the site of overflow from the breathing circuit. When children had invasive mechanical ventilation, the flowmeter was recalibrated after external flow connection. The gas scavenging filter was installed on the expiratory circuit. Sevoflurane inhaled concentration and $\mathrm{FiO}_{2}$ were monitored (Phillips M1026B, Boeblingen, Germany) on output of the heater. Insufflation started with $1 \%$ sevoflurane, and was progressively increased by $0.5 \%$ steps until the patient was asleep, as determined by closed eyes, absence of motor response to gentle handling and lost of tonus. Throughout the procedure, sevoflurane concentration was increased by $0.5 \%$ if movement complicating the procedure and due to stimulation occurred. Inversely, sevoflurane was decreased by $0.5 \%$ if MAP decrease of $30 \%$ of baseline value or if apnea $(>30 \mathrm{~s}$ and $\mathrm{SpO} 2<85 \%$ ) occurred.

\section{PICC placement}

Twenty-four gauge silastic catheters (Epicutaneo - cava - katheter, Vygon, Germany) were used for all babies. The procedure was performed by a junior or senior neonatal intensivist; if placement failed after 4 attempts, a second operator (senior intensivist) was called in. The procedure was considered successful when the catheter was introduced in the vein and advanced to the expected distance. 


\section{Data collection}

Data were reported by an independent observer (senior intensivist). Duration of the procedure was recorded as the time between the first skin puncture and the end of dressing placement. $\mathrm{FiO}_{2}, \mathrm{SpO} 2, \mathrm{HR}, \mathrm{RR}, \mathrm{tcCO} 2$ and MAP were prospectively recorded before (basal measurements) and during the procedure. All data were printed and analyzed under blinded conditions, to determine maximal and minimal values (max and min), occurrence of tachycardia (HR $>20 \%$ of basal value or $>180 / \mathrm{min}$ ), hypotension (MAP $<$ gestational age in weeks), hypertension (MAP>30\% of basal value), apnea ( $>30 \mathrm{sec}$ ), and bradycardia $(\mathrm{HR}<100 / \mathrm{min})$.

Movements during the procedure were recorded as little or none ( 0 or 1 movement, regarded as not complicating the procedure), moderate (2 to 5 occurrences, which complicated the procedure), or frequent ( $>5$ occurrences which complicated the procedure). We also recorded sevoflurane concentration during the procedure; the experience of the operator; the total number of punctures; and the number of punctures outside the locally anaesthetized zone; clonic movements, laryngospasm and other adverse events. At the end of each procedure, the operator scored the ease in carrying out that procedure as "easy" "intermediate" or "difficult". Glycemia by hemoglucotest (Accu-Chek Performa, Roche Diagnostics) was measured immediately after the end of each procedure, SpO2, HR and MAP were continuously monitored for 4 hours after the end of each procedure. Serious complications (death, cerebral hemorrhage, bacteremia, bronchopulmonary dysplasia, enterocolitis, and persistent ductus arteriosus) during the stay in the NICU were also recorded. Statistical analysis 
The number of patients was calculated to show a decrease in the mean duration of the procedure from 60 to $45 \mathrm{~min}$ in the sevoflurane group with standard deviation of $20 \mathrm{~min}$, risk $\alpha=0.05$ and risk $\beta=0.8$. A minimum of 29 patients per group was required.

The data are expressed as the mean \pm SD for normally distributed data and median with interquartile range (IQR) for non-normally distributed data. Differences between and within the 2 groups were assessed using t-test for the continuous variables and chi square tests for categorical variables. Fisher exact tests were used when previous tests were not applicable. For repeated measures, differences between groups and within-groups were assessed by oneway repeated measures ANOVA using general linear model.

\section{Results}

Thirty children were included in each group between September 2006 and May 2008. One child in the GNNS group was excluded due to a severe congenital encephalopathy. The baseline demographic and clinical characteristics of the two groups were similar. The operator was a junior in most cases (table 1). Mean maximal and minimal inhaled sevoflurane concentrations used in the IS group were $2.7 \pm 0.8$ and $1.0 \pm 0.7$ respectively.

\section{PICC placement data (Table 2)}

There were no differences between groups in mean duration $(\mathrm{p}=0.83)$ of procedure, total number of punctures and number of punctures outside the locally anaesthetized zone. A second operator was required in the same proportion in each group. Evaluation of the ease in performing the procedure showed no significant difference between two groups (Table 2). Success rate of PICC placement was similar in the 2 groups $(\mathrm{p}=0.3)$. In one case in the GNNS group and none in the IS group the catheter was inserted in the vein but not advanced to the expected distance. 


\section{Efficacy and tolerance of treatments (Table 3 and 4)}

Occurrence of movements complicating the procedure were significantly different between groups $(\mathrm{p}=0.024)$. Immobility during the procedure was significantly more frequent in IS group ( $p=0,017)$ (Fig. 1). Mean HRmax was significantly higher in children with movements that complicated the procedure $(\mathrm{p}=0.003)$. For 2 children in the GNNS group and 1 in the IS group, arterial pressure measures were lost. MAP and HR increased significantly in the GNNS and the maximum values were significantly higher in the GNNS than in the IS group. MAPmin was lower in the IS group (Table 3) but hypotension occurrence was not significantly different. Tachycardia, bradycardia and hypertension were more frequent in the GNNS group (Table 4).

The occurrence of apnea and desaturation was not different (Table 4). Apneas in the IS group were always rapidly reversible with diminution of sevoflurane concentration.

Two neonates in the IS group experienced punctual clonic movements which stopped with decrease of sevoflurane. In one child, sevoflurane had to be stopped because repeated clonic movements occurred. Clinical evolution was normal for this child.

Patent ductus arteriosus was diagnosed in 4 neonates in each group. Only one in the GNNS group and none in the IS group developed hypotension. Inversely, one in the IS group and none in the GNNS group developed hypertension. None of these eight children developed tachycardia. One of them in the IS group developed desaturation requiring to increase $\mathrm{FiO} 2$ to $28 \%$.

\section{Post procedure survey}

Glycemia at the end of the procedure did not differ between the IS $(8.7 \mathrm{mmol} / \mathrm{L})$ and GNNS (7.5 mmol/l) groups (ns). One infant in the IS group died at 21 days of life. The death 
1

2

3

4

5

6

7

8

9

10

11

12

13

14

15

16

17

18

19

20

21

22

23

24

25

26

27

28

29

30

31

32

33

34

35

36

37

38

39

40

41

42

43

44

45

46

47

48

49

50

51

52

53

54

55

56

57

58

59

60

was due to septic shock. Two other infants in the IS group developed intra ventricular hemorrhage (Grade I). Among them, one had not developed hypotension during the procedure. Neither of these complications occurred in the GNNS group. Occurrence of others complications were similar in the 2 groups. 


\section{Discussion}

We compare for the first time, sevoflurane to GNNS to decrease movements, facilitate the procedure and prevent procedural pain effects in neonates during PICC placement. In this study we failed to difference in the duration of the procedure and in the success placement rate. These findings are in agreement with previous results of studies that evaluated pain treatments during PICC placement $(3,5,9)$. Probably that others factors than limbs movements explain the difficulty to insert and advance the catheters. It could be visibility and fragility of veins, presence of oedema in the first days of life or experience of operators. Furthermore, according to the site of puncture, it can be difficult to thread the catheter in the vein. This last situation occurred one time in our study.

We found however that sevoflurane deep sedation strongly decreased hemodynamic pain manifestations and movements during the procedure. We choose GNNS as referent treatment because they are widely used and have been described as effective in avoiding procedural pain in neonates $(10)$. We found that this non-pharmacological treatment failed to prevent pain-related hemodynamic modifications in more than half the patients. Topical analgesia has been shown effective in preventing pain caused by skin puncture $(9,11)$, but as we observed, punctures outside the anaesthetized zone are frequent. In addition, topical analgesia remains inactive during stressful parts of the procedure, and a recent study showed few differences in pain score between topical analgesia and no treatment (3). As highlighted in this study, duration of procedure and success placement rate are not improved by sedation and immobility.

Intravenous opioids, have also been used to prevent pain due to PICC placement. Morphine with topical tetracaine was more effective than tetracaine alone or than no treatment in preventing pain (3). Morphine, however, has been associated with increased ventilatory 
requirements, and boluses of morphine have been responsible for hypotension. One important drawback of morphine is its non-controlled and prolonged action (4). Remifentanil, which has a much shorter contextual half life, has been found to decrease pain score compared with sucrose and non-nutritive sucking, without hemodynamic or respiratory adverse effects (5). Nevertheless, the remifentanil dose in this study was low and mean NIPS scores $>3$. Use of higher doses of opioids could lead to respiratory complications.

Sévoflurane is an anaesthetic drug and induces deep sedation such that infants could not feel the discomfort associated with handling. Moreover, halogenated anaesthetics, by acting on neurotransmission in the spinal cord, can decrease synaptic transmission and contribute to provide immobility (12) and central analgesia (13).

Although we used $<1$ MAC concentrations of sevoflurane, we observed that half the children develop hypotension in the IS group vs one third in the GNNS group. The difference was not significant but MAPmin was significantly lower in the IS group. The definition of hypotension in previous studies was based on clinician practice and defined by need of treatment. Since there are no recommendations regarding ideal blood pressure during general anaesthesia, we used a disputable but objective definition, daily applicated in clinical practice in NICU. It may have increased the apparent rate of hypotension compared with previous studies. Careful hemodynamic monitoring by trained and attentive clinicians is required to titrate sevoflurane concentration according to its clinical effects.

We observed clonic movements in 4 neonates. Sevoflurane is known to induce epileptiform cerebral activity particularly with high inhaled concentrations (14). Despite the low sevoflurane concentrations used, clonic movements could be linked to sevoflurane administration. Nevertheless, interpretation of clonic movements in neonates is difficult and do not correspond to epilepsy in many cases (15). Because for 3 neonates clonic movements stopped rapidly sevoflurane was continued. In 1 case repeated episodes require to stop 
sevoflurane. Long term neurotoxicity of general anesthetics is an other concern for sevoflurane use. Recent works had shown neurotoxicity of general anaesthetics on animals developing brain, with impairment of cognitive functions and behavioural troubles (16). More worrying, two recent studies suggest that repeated anaesthesia or anaesthesia in young children and infants could be associated with learning disabilities and/or disturbed neurobehavioral development $(17,18)$. Despite important limitations, these studies would lead anaesthetists to find solutions to avoid anaesthetics' use in this population. On the other hand, repetitive untreated pain is responsible for neuronal cell death in animals. In human babies, sensitization and hyperalgesia phenomenon had been proved and recently, pain in preterm neonates has been associated with poorer cognitive and motor development at 8 and 18 month (19). As debated (20), clinicians are confronted to an awful choice between pain and analgesia.

Sevoflurane administration to avoid pain manifestation could be called "anaesthesia" rather than "deep sedation". We chose "deep sedation" in this situation because sevoflurane is titrated to limit occurrence of movement and avoid adverse effects. Maximum concentration of sevoflurane was $2.7(2-3) \%$. Nevertheless because we have measured inhaled concentrations, and because nasal CPAP administration is associated with gas leak, exhaled concentrations were probably much lower. According to the American Society of Anesthesiologists, the state procured in this case is a "deep sedation" (21). Nevertheless, the difference between anaesthesia and deep sedation remains very thin (22) and inhaled sevoflurane with spontaneously breathing requires the same equipments, facilities and skills than general anesthesia.

Furthermore this study had several limitations. Treatment could not be blinded, since sevoflurane has a specific odour. Lack of blinding may have affected time measurements, number of operators or number of punctures. Hemodynamic data were analyzed under blinded 
conditions using recorded and printed data. The occurrence of movements and the conditions required to perform PICC placement are the most sensitive to this methodological problem. Nevertheless, despite a lack of blinding, operators did not consider conditions better with sevoflurane, in agreement with treatment duration.

Another important limitation was the lack of pain score measurement. The premature infant pain profile score (23) or douleur aigue du nouveau-né (24) could be used. However, these measurements are difficult to make under aseptic conditions and when the child is covered by a sterile sheet. Taped video could have been used but this study was not initially designed to compare efficacy of treatments on pain because in our experience, efficacy was clinically evident. Despite the lack of validated score, we evaluated pain by indirect means, including HR, MAP and movements, with HR modification showing the highest correlation with pain score (25).

Finally, environmental pollution and potential personnel exposure to sevoflurane require ventilated rooms and scavenging gas system on the output of breathing circuit. Despite the precautions and the low concentration used, operators could sometimes smell sevoflurane vapors near of the child; we have to work, to resolve this inconvenient.

In conclusion, IS do not improve conditions for PICC placement compared with GNNS in $>28$ weeks of gestational age, but is effective in preventing pain-related effects during PICC placement. In our daily practice, inhaled sevoflurane maintaining spontaneous breathing is now a very useful mean to prevent pain and its consequences in neonates. However, sevoflurane is associated with decrease of MAP and require careful hemodynamic monitoring. Moreover, it is essential to keep in mind its potential neurotoxicity and potential long terms clinical effects. 
Acknowledgements: we thank CNP Assurances for supporting in part this research.

1 
1. Carbajal R, Rousset A, Danan C, Coquery S, Nolent P, Ducrocq S, et al. Epidemiology and treatment of painful procedures in neonates in intensive care units. JAMA $2008 \mathrm{Jul}$ 2;300:60-70.

2. Stevens B, Yamada J, Ohlsson A. Sucrose for analgesia in newborn infants undergoing painful procedures. Cochrane Database Syst Rev. 2004;(3):CD001069.

3. Taddio A, Lee C, Yip A, Parvez B, McNamara PJ, Shah V. Intravenous morphine and topical tetracaine for treatment of pain in [corrected] neonates undergoing central line placement. JAMA 2006 ;295:793-800.

4. Anand KJS, Anderson BJ, Holford NHG, Hall RW, Young T, Shephard B, et al. Morphine pharmacokinetics and pharmacodynamics in preterm and term neonates: secondary results from the NEOPAIN trial. Br J Anaesth. 2008 ;101:680-9.

5. Lago P, Tiozzo C, Boccuzzo G, Allegro A, Zacchello F. Remifentanil for percutaneous intravenous central catheter placement in preterm infant: a randomized controlled trial. Paediatr Anaesth. 2008 ;18:736-44.

6. Hassid S, Nicaise C, Michel F, Vialet R, Thomachot L, Lagier P, et al. Randomized controlled trial of sevoflurane for intubation in neonates. Paediatr Anaesth. 2007; $17: 1053-8$

7. De Sanctis Briggs V. Magnetic resonance imaging under sedation in newborns and infants: a study of 640 cases using sevoflurane. Paediatr Anaesth. 2005 ;15:9-15.

8. Vialet R, Michel F, Hassid S, Di Marco J, Martin C. Sevoflurane for central venous catheterization in non-intubated neonates. Indian J Pediatr 2009 ;76:273-7

9. Lemyre B, Sherlock R, Hogan D, Gaboury I, Blanchard C, Moher D. How effective is tetracaine $4 \%$ gel, before a peripherally inserted central catheter, in reducing procedural pain in infants: a randomized double-blind placebo controlled trial. BMC Med. 2006;4:11.

10. Taddio A, Shah V, Hancock R, Smith RW, Stephens D, Atenafu E, et al. Effectiveness of sucrose analgesia in newborns undergoing painful medical procedures. CMAJ. $2008 \mathrm{Jul}$ $1 ; 179: 37-43$.

11. Garcia OC, Reichberg S, Brion LP, Schulman M. Topical anesthesia for line insertion in very low birth weight infants. J Perinatol. 17:477-80.

12. Matute E, Rivera-Arconada I, López-García JA. Effects of propofol and sevoflurane on the excitability of rat spinal motoneurones and nociceptive reflexes in vitro. Br J Anaesth. $2004 ; 93: 422-427$.

13. Georgiev SK, Wakai A, Kohno T, Yamakura T, Baba H. Actions of norepinephrine and isoflurane on inhibitory synaptic transmission in adult rat spinal cord substantia gelatinosa neurons. Anesth. Analg. 2006 Jan;102:124-128. 
14. Constant I, Seeman R, Murat I. Sevoflurane and epileptiform EEG changes. Paediatr Anaesth. 2005 ;15:266-274.

15. Malone A, Ryan CA, Fitzgerald A, Burgoyne L, Connolly S, Boylan GB. Interobserver agreement in neonatal seizure identification. Epilepsia. 2009 ;50:2097-2101.

16. Patel P, Sun L. Update on neonatal anesthetic neurotoxicity: insight into molecular mechanisms and relevance to humans. Anesthesiology. 2009 ;110:703-708.

17. Kalkman CJ, Peelen L, Moons KG, Veenhuizen M, Bruens M, Sinnema G, et al. Behavior and development in children and age at the time of first anesthetic exposure. Anesthesiology. $2009 ; 110: 805-812$.

18. Wilder RT, Flick RP, Sprung J, Katusic SK, Barbaresi WJ, Mickelson C, et al. Early exposure to anesthesia and learning disabilities in a population-based birth cohort. Anesthesiology. 2009 ; 110:796-804.

19. Grunau RE, Whitfield MF, Petrie-Thomas J, Synnes AR, Cepeda IL, Keidar A, et al. Neonatal pain, parenting stress and interaction, in relation to cognitive and motor development at 8 and 18 months in preterm infants. Pain. 2009 ;143:138-146.

20. Mancuso T, Burns JP. Ethical concerns in the management of pain in the neonate. Pediatric Anesthesia. 2009;19:953-957.

21. American Society of Anesthesiologists. Practice guidelines for sedation and analgesia by non-anesthesiologists. Anesthesiology. 2002;96:1004-1017.

22. $\mathrm{Ng} \mathrm{A}$. Sevoflurane sedation in infants--a fine line between sedation and general anesthesia. Paediatr Anaesth. $2005 ; 15: 1-2$.

23. Stevens B, Johnston C, Petryshen P, Taddio A. Premature Infant Pain Profile: development and initial validation. Clin J Pain. 1996;12:13-22.

24. Carbajal R, Paupe A, Hoenn E, Lenclen R, Olivier-Martin M. DAN : une échelle comportementale d'évaluation de la douleur aiguë du nouveau-né. Arch Pediatr. 1997 ;4:623-8.

25. Gaspardo CM, Chimello JT, Cugler TS, Martinez FE, Linhares MBM. Pain and tactile stimuli during arterial puncture in preterm neonates. Pain. 2008 ;140:58-64. 
Figure 1: Occurrence of movements during the procedure

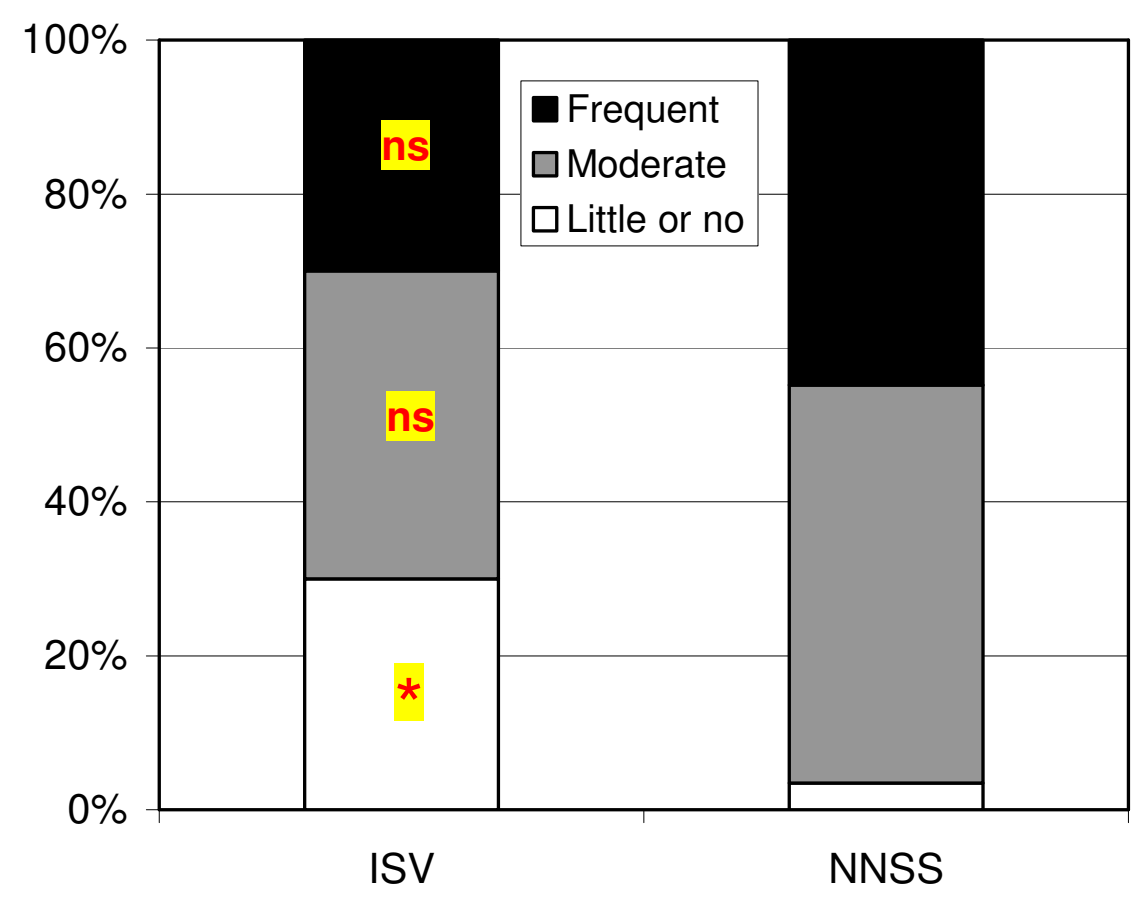

*: $\mathrm{p}=0.017$ compared with other group ns: non significant

Abbreviations: GNNS, glucose and non-nutritive sucking; IS, inhaled sevoflurane 
$\underline{\text { Table 1: Patient characteristics }}$

\begin{tabular}{|lccc|}
\hline Population & GNNS & IS & p \\
\hline n & 29 & 30 & \\
\hline Gestational Age (weeks), mean \pm SD & $29.9 \pm 1,6$ & $29.7 \pm 3.1$ & 0.77 \\
\hline Age (d), mean \pm SD & $1.7 \pm 0.8$ & $2.0 \pm 0.8$ & 0.11 \\
\hline Gender F/M (n) & $15 / 14$ & $17 / 13$ & 0.70 \\
\hline Weight (g), mean \pm SD & $1267 \pm 330$ & $1338 \pm 451$ & 0.50 \\
\hline CRIB2 score, mean \pm SD & $3.6 \pm 2.7$ & $3.8 \pm 2.7$ & 0.81 \\
\hline CPAP (n/\%) & $24 / 82.7$ & $27 / 90.0$ & 0.25 \\
\hline IMV (n/\%) & $5 / 17.3$ & $3 / 10.0$ & 0.71 \\
\hline
\end{tabular}

Abbreviations: GNNS, Glucose and non-nutritive sucking; IS, inhaled sevoflurane; IMV, invasive mechanical ventilation 
Table 2: Characteristics of the procedure

\begin{tabular}{|c|c|c|c|}
\hline & IS & GNNS & $\mathbf{p}$ \\
\hline Trained operator (n/\%) & $7 / 23.3$ & $11 / 37.9$ & 0.22 \\
\hline Second operator required $(\mathrm{n} / \%)$ & $11 / 36.6$ & $11 / 37.9$ & 0.92 \\
\hline Successful placement $(\mathrm{n} / \%)$ & $27 / 90$ & $24 / 82.7$ & 0.25 \\
\hline \multicolumn{4}{|l|}{ Number of punctures / child } \\
\hline Total (mean \pm sd) & $3.8 \pm 2.9$ & $3.7 \pm 2.7$ & 0.84 \\
\hline Outside of anaesthetized zone (mean \pm sd) & $1.0 \pm 1.1$ & $1.3 \pm 1.5$ & 0.52 \\
\hline Duration of procedure (min) & $45(33-68)$ & $50(25-71)$ & 0.84 \\
\hline \multicolumn{4}{|l|}{ Ease to carry out the procedure } \\
\hline $\operatorname{Easy}(n / \%)$ & $21 / 70.0$ & $14 / 48.2$ & \multirow{3}{*}{0.13} \\
\hline Intermediate (n/\%) & $6 / 20.0$ & $13 / 44.8$ & \\
\hline Difficult (n/\%) & $3 / 10.0$ & $2 / 6.9$ & \\
\hline
\end{tabular}

Abbreviations; GNNS, glucose and non-nutritive sucking; IS, inhaled sevoflurane 
Table 3: Hemodynamic and respiratory parameters before analgesia (basal) and during the procedure (maximal and minimal values)

\begin{tabular}{|c|c|c|c|}
\hline MAP & Basal & Minimal & Maximal \\
\hline IS & $44(39-51)$ & $27(23-32)^{a}$ & $41(38-47)$ \\
\hline GNNS & $43(36-46)$ & $34(28-42)^{a, e}$ & $55(49-66)^{a, d}$ \\
\hline HR & Basal & Minimal & Maximal \\
\hline IS & $143(136-154)$ & $126(118-140)^{a}$ & $151(138-157)$ \\
\hline GNNS & $146(136-154)$ & $135(110-142)^{a}$ & $175(168-180)^{a}$ \\
\hline TcCO2 & Basal & Minimal & Maximal \\
\hline IS & $43(39-47)$ & $45(42-48)$ & $49(45-52)$ \\
\hline GNNS & $43(38-47)$ & $40(34-44)^{b}$ & $46(43-52)^{c}$ \\
\hline FR & Basal & Minimal & Maximal \\
\hline IS & $44(37-51)$ & $36(29-45)^{c}$ & $75(56-80)^{a}$ \\
\hline GNNS & $48(41-55)$ & $35(26-40)^{b}$ & $69(60-80)^{a}$ \\
\hline $\mathrm{SpO2}$ & Basal & Minimal & Maximal \\
\hline IS & $98(96-100)$ & $92(85-95)^{b}$ & $99(98-100)^{c}$ \\
\hline GNNS & $98(96-99)$ & $87(82-91)^{a}$ & $100(98-100)^{c}$ \\
\hline $\mathrm{FiO}_{2}$ & Basal & Minimal & Maximal \\
\hline IS & $21(21-21)$ & $21(21-21)$ & $21(21-24)$ \\
\hline GNNS & $21(21-21)$ & $21(21-21)$ & $21(21-30)$ \\
\hline
\end{tabular}

All data reported as median (range).

Abbreviations: GNNS, glucose and non-nutritive sucking; IS, inhaled sevoflurane.
a: $\mathrm{p}<0.001 ; \mathrm{b}: \mathrm{p}<0.01 ; \mathrm{c}: \mathrm{p}<0.05$ vs basal
$\mathrm{d}: \mathrm{p}<0.001 ; \mathrm{e}: \mathrm{p}<0.01$ vs IS group 
Table 4: Neonates with hemodynamic and respiratory difficulties during PICC placement

\begin{tabular}{|l|c|c|l|}
\hline & IS & GNNS & \\
\hline Hypertension n/\% & $2 / 6.9$ & $15 / 55.5$ & $p=0.003$ \\
\hline Hypotension n/\% & $16 / 55.5$ & $9 / 33.3$ & $p=0.06$ \\
\hline Tachycardia n/\% & $0 / 0.0$ & $15 / 51.7$ & $p<0.001$ \\
\hline Bradycardia n/\% & $1 / 3.3$ & $7 / 24.1$ & $p=0.02$ \\
\hline Desaturation n/\% & $6 / 20.7$ & $12 / 41.4$ & $p=0.08$ \\
\hline Apnea n/\% & $4 / 13.3$ & $1 / 3.4$ & $p=0.17$ \\
\hline
\end{tabular}

Abbreviations: GNNS, glucose and non-nutritive sucking; IS, inhaled sevoflurane 


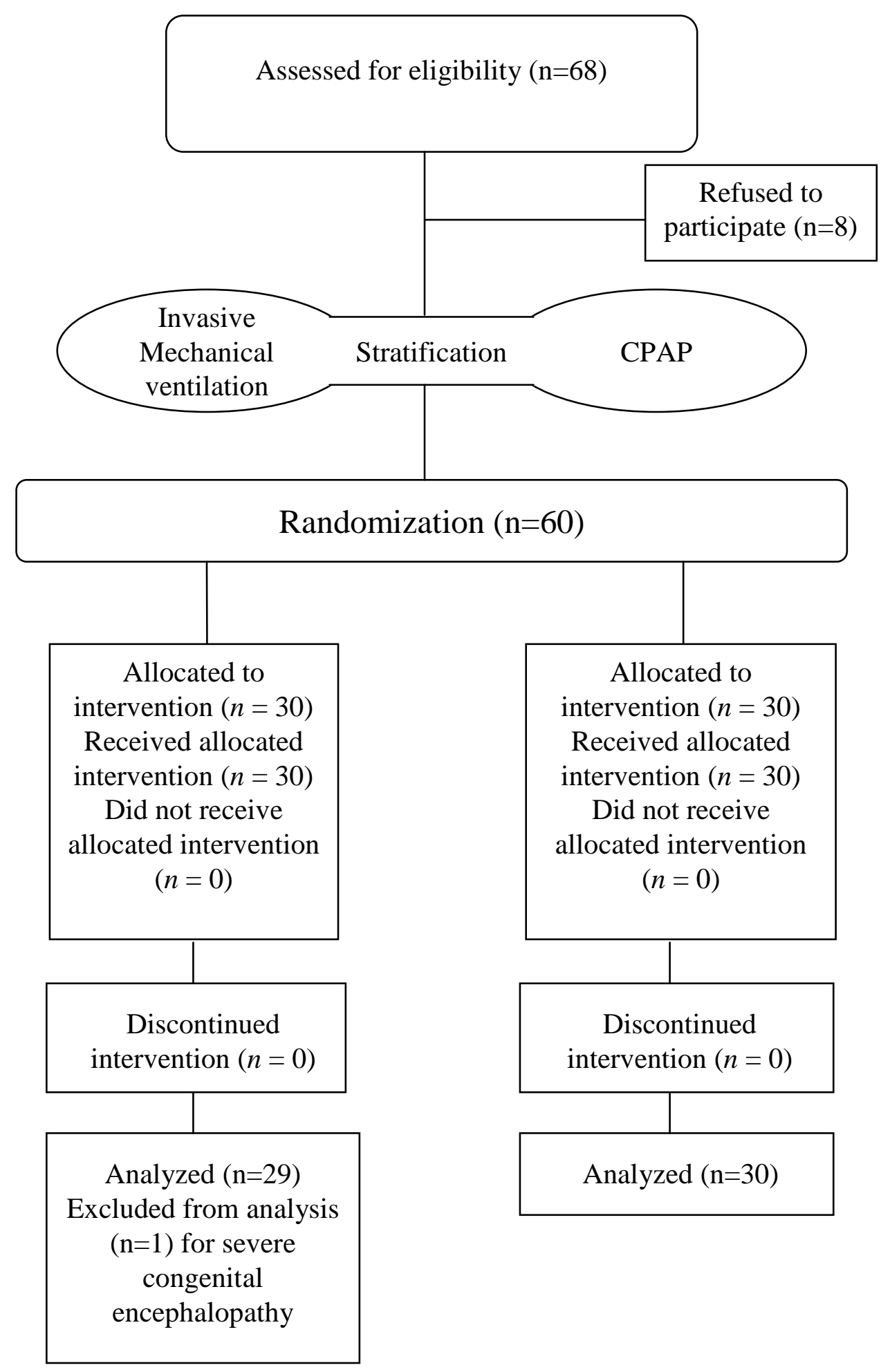

Flow of patients 


\section{CONSORT Statement 2001 - Checklist $A$ Items to include when reporting a randomized trial}

\begin{tabular}{|c|c|c|c|}
\hline $\begin{array}{l}\text { PAPER SECTION } \\
\text { And topic }\end{array}$ & Item & Descriptor & $\begin{array}{l}\text { Reported on } \\
\text { Page \# }\end{array}$ \\
\hline TITLE \& ABSTRACT & 1 & $\begin{array}{l}\text { How participants were allocated to interventions (e.g., "random } \\
\text { allocation", "randomized", or "randomly assigned"). }\end{array}$ & $1-2$ \\
\hline $\begin{array}{l}\text { INTRODUCTION } \\
\text { Background }\end{array}$ & 2 & Scientific background and explanation of rationale. & $3-4$ \\
\hline $\begin{array}{l}\text { METHODS } \\
\text { Participants }\end{array}$ & 3 & $\begin{array}{l}\text { Eligibility criteria for participants and the settings and locations } \\
\text { where the data were collected. }\end{array}$ & 4 \\
\hline Interventions & 4 & $\begin{array}{l}\text { Precise details of the interventions intended for each group and } \\
\text { how and when they were actually administered. }\end{array}$ & $4-5$ \\
\hline Objectives & 5 & Specific objectives and hypotheses. & \\
\hline Outcomes & 6 & $\begin{array}{l}\text { Clearly defined primary and secondary outcome measures and, } \\
\text { when applicable, any methods used to enhance the quality of } \\
\text { measurements (e.g., multiple observations, training of } \\
\text { assessors). }\end{array}$ & 3 \\
\hline Sample size & 7 & $\begin{array}{l}\text { How sample size was determined and, when applicable, } \\
\text { explanation of any interim analyses and stopping rules. }\end{array}$ & 6 \\
\hline $\begin{array}{l}\text { Randomization -- } \\
\text { Sequence generation }\end{array}$ & 8 & $\begin{array}{l}\text { Method used to generate the random allocation sequence, } \\
\text { including details of any restrictions (e.g., blocking, stratification) }\end{array}$ & 4 \\
\hline $\begin{array}{l}\text { Randomization -- } \\
\text { Allocation } \\
\text { concealment }\end{array}$ & 9 & $\begin{array}{l}\text { Method used to implement the random allocation sequence (e.g., } \\
\text { numbered containers or central telephone), clarifying whether the } \\
\text { sequence was concealed until interventions were assigned. }\end{array}$ & 4 \\
\hline $\begin{array}{l}\text { Randomization -- } \\
\text { Implementation }\end{array}$ & 10 & $\begin{array}{l}\text { Who generated the allocation sequence, who enrolled } \\
\text { participants, and who assigned participants to their groups. }\end{array}$ & 4 \\
\hline Blinding (masking) & 11 & $\begin{array}{l}\text { Whether or not participants, those administering the } \\
\text { interventions, and those assessing the outcomes were blinded to } \\
\text { group assignment. If done, how the success of blinding was } \\
\text { evaluated. }\end{array}$ & - \\
\hline Statistical methods & 12 & $\begin{array}{l}\text { Statistical methods used to compare groups for primary } \\
\text { outcome(s); Methods for additional analyses, such as subgroup } \\
\text { analyses and adjusted analyses. }\end{array}$ & 6 \\
\hline $\begin{array}{c}\text { RESULTS } \\
\text { Participant flow }\end{array}$ & 13 & $\begin{array}{l}\text { Flow of participants through each stage (a diagram is strongly } \\
\text { recommended). Specifically, for each group report the numbers } \\
\text { of participants randomly assigned, receiving intended treatment, } \\
\text { completing the study protocol, and analyzed for the primary } \\
\text { outcome. Describe protocol deviations from study as planned, } \\
\text { together with reasons. }\end{array}$ & 7 \\
\hline Recruitment & 14 & Dates defining the periods of recruitment and follow-up. & 7 \\
\hline Baseline data & 15 & Baseline demographic and clinical characteristics of each group. & 7 - Table1 \\
\hline Numbers analyzed & 16 & $\begin{array}{l}\text { Number of participants (denominator) in each group included in } \\
\text { each analysis and whether the analysis was by "intention-to- } \\
\text { treat". State the results in absolute numbers when feasible (e.g., } \\
10 / 20 \text {, not } 50 \% \text { ). }\end{array}$ & 7 \\
\hline $\begin{array}{l}\text { Outcomes and } \\
\text { estimation }\end{array}$ & 17 & $\begin{array}{l}\text { For each primary and secondary outcome, a summary of results } \\
\text { for each group, and the estimated effect size and its precision } \\
\text { (e.g., } 95 \% \text { confidence interval). }\end{array}$ & $7-8$ \\
\hline Ancillary analyses & 18 & $\begin{array}{l}\text { Address multiplicity by reporting any other analyses performed, } \\
\text { including subgroup analyses and adjusted analyses, indicating } \\
\text { those pre-specified and those exploratory. }\end{array}$ & $7-8$ \\
\hline Adverse events & 19 & $\begin{array}{l}\text { All important adverse events or side effects in each intervention } \\
\text { group. }\end{array}$ & 8 \\
\hline $\begin{array}{l}\text { DISCUSSION } \\
\text { Interpretation }\end{array}$ & 20 & $\begin{array}{l}\text { Interpretation of the results, taking into account study } \\
\text { hypotheses, sources of potential bias or imprecision and the } \\
\text { dangers associated with multiplicity of analyses and outcomes. }\end{array}$ & $9-10-11$ \\
\hline Generalizability & 21 & Generalizability (external validity) of the trial findings. & - \\
\hline Overall evidence & 22 & $\begin{array}{l}\text { General interpretation of the results in the context of current } \\
\text { evidence. }\end{array}$ & $9-10-11$ \\
\hline
\end{tabular}

